\title{
Maternal Satisfaction with Intrapartum Nursing Care and Its Associated Factors among Mothers Who Gave Birth in Public Hospitals of North Wollo Zone, Northeast Ethiopia: Institution-Based Cross-Sectional Study
}

\author{
Asmamaw Demis $\mathbb{D}^{1},{ }^{1}$ Ribka Nigatu, ${ }^{1}$ Derebe Assefa, ${ }^{1}$ and Getnet Gedefaw $\mathbb{D}^{2}$ \\ ${ }^{1}$ Department of Nursing, College of Health Sciences, Woldia University, P.O. Box: 400, Woldia, Ethiopia \\ ${ }^{2}$ Department of Midwifery, College of Health Sciences, Woldia University, P.O.Box:400, Woldia, Ethiopia \\ Correspondence should be addressed to Asmamaw Demis; asmamawdemis@gmail.com
}

Received 28 December 2019; Revised 11 March 2020; Accepted 20 March 2020; Published 27 April 2020

Academic Editor: Marco Scioscia

Copyright (c) 2020 Asmamaw Demis et al. This is an open access article distributed under the Creative Commons Attribution License, which permits unrestricted use, distribution, and reproduction in any medium, provided the original work is properly cited.

\begin{abstract}
Background. Now a day, satisfaction had been identified as the major index to assess the quality of health-care provision in the world including Ethiopia. Mothers judge the quality of intrapartum care received based on their satisfaction with the services provided, thus influencing their utilization of the available health facilities. Therefore, this study aimed to assess maternal satisfaction with intrapartum care and associated factors among mothers who gave birth in public hospitals in North Wollo Zone, Northeastern Ethiopia, 2019. Methods. Institutional-based cross-sectional quantitative study was conducted in public hospitals of North Wollo Zone, and a total of 398 study participants were selected by using a systematic random sampling method. Data was collected using a standardized questionnaire by direct interviewing of study participants, and data was analyzed using SPSS 24 versions to determine the frequency of variables. Logistic regression was carried out to identify factors associated with maternal satisfaction. Results. From the total of 398 study participants, about 51\% of women were satisfied with the hospital-based intrapartum nursing care. Being rural in residency (AOR: 2.03; 95\% CI: 1.05-3.93), time to be seen by healthcare providers (AOR: 2.82; 95\% CI: 1.46-5.46), having history of ANC follow-up (AOR: 3.73; 95\% CI: 1.12-12.57), and getting adequate meal (AOR: 3.96; 95\% CI: 1.13-13.83) had showed statistical significant association with maternal satisfaction. Conclusion. In this study, the overall maternal satisfaction with intrapartum nursing care was low. Therefore, improving ANC follow-up, early examined by health-care providers, and getting adequate meal while in labour and delivery might enhance women satisfaction with intrapartum nursing care services.
\end{abstract}

\section{Introduction}

Intrapartum nursing care is the care given by nurses and midwives for labouring mother during labour and delivery [1]. Even though the primary target of the United Nations' Sustainable Development Goal (SDG3) is to reduce the global maternal mortality rate to less than 70 per 100,000 live births, the quality of intrapartum care in most low- and middle-income countries was chronically poor, and this had been identified as one of the precursors to the unacceptably high maternal mortality rate in low- and middle-income countries [1]. The World Health Organization reported that approximately more than eight hundred fifty women die from preventable causes related to childbirth every day, with $99 \%$ of all these maternal deaths occurring in low- and middle-income countries [2].

Maternal satisfaction with intrapartum nursing care measures the ability of services to meet consumers' expectations, and it is an important determinant of the choice of health facility and its future utilization for labour and delivery services [3-7]. In Ethiopia, there are increasing needs of client-centered care and had been a growing consensus that patient service quality perceptions are critical for maintaining and monitoring the quality of health care [8-10]. 
According to WHO, more than 600,000 women die each year from complications arising from pregnancy and labour and delivery. The majority of maternal mortality occurred in sub-Saharan Africa $(162,000)$ and Southern Asia $(83,000)$ with these two regions accounted for $85 \%$ of global burden, with sub-Saharan Africa alone accounting for $56 \%$. The estimated pregnancy-related mortality ratio was 412 deaths per 100,000 live births in Ethiopia [2, 11].

Different studies conducted in developed and developing countries including Ethiopia showed that ANC follow-up, educational status, waiting time, availability of basic drugs, cleanliness of the environment, delivery room and wards, cost paid to service and waiting area, privacy, educational status, and health providers' technical competence were the major factors associated with maternal satisfaction with intrapartum nursing care [8, 12-19].

In Ethiopia, among the total live births in the 5 years preceding the survey, $50 \%$ were delivered by a skilled provider and $48 \%$ were delivered in a health facility [20]. Only, provision of maternal health service does not improve maternal health; as a result, the World Health Organization promotes skilled attendance at every birth to reduce maternal mortality and recommends that women's satisfaction is the most important index to improve the quality and effectiveness of health-care provision [21]. Now a day, most patients in our country and specifically in public hospitals of North Wollo Zone complain about hospital services, particularly on delivery services. Despite having many studies done elsewhere, there is a paucity of data concerning maternal satisfaction with intrapartum nursing care in Ethiopia; particularly, there is a dearth of study in Northeastern Ethiopia. Therefore, this study aimed to assess mothers' satisfaction with intrapartum care and factors associated with it among mothers who gave birth at a public hospital in North Wollo Zone, Northeastern Ethiopia.

\subsection{Objectives}

\subsubsection{Specific Objectives}

(i) To determine the magnitude of maternal satisfaction with intrapartum nursing care among mothers who gave birth in public hospitals of North Wollo Zone, Northeast Ethiopia.

(ii) To identify factors associated with mothers satisfaction with intrapartum nursing care among mothers who gave birth in public hospitals of North Wollo Zone, Northeast Ethiopia.

\section{Methods and Materials}

2.1. Study Setting, Design, and Period. An institution-based cross-sectional quantitative study design was carried out at public hospitals in North Wollo Zone, Amhara National Regional State from January 01 to February 30, 2019. North Wollo Zone is found in Amhara region with a capital city of Woldia that is found $521 \mathrm{~km}$ away from Addis Ababa and $360 \mathrm{~km}$ form Bahirdar. Based on the 2007 Census conducted by the Central Statistical Agency of Ethiopia [22], the total population of North Wollo Zone was 1,500,303, an increase of $19.04 \%$ over the 1994 census, of whom 752,895 are men and 747,408 women, respectively. There are five public hospitals in North Wollo Zone, namely, Woldia General Hospital, Kobo Primary Hospital, Lalibela Primary Hospital, Meket Primary Hospital, and Wadila Primary Hospital. The hospitals are open for 24 hours in a day to provide curative, emergency, maternal, and child health services. Regarding health services, there are six hospitals, sixty-five health centers, and two hundred seventy-five health posts providing services to the community according to North Wollo Zone Health Office. Annual report from North Wollo Zone Health Office in 2019 indicated that the health coverage of institutional delivery was $78 \%$.

2.2. Source Population and Study Population. The source population were all women who visited public hospitals in North Wollo Zone for delivery service, and all systematically selected women who gave birth at public hospitals during the study period were the study population.

2.3. Inclusion and Exclusion Criteria. Women who gave birth in the selected hospitals and discharged from postnatal ward during the data collection period were included, whereas women who were seriously ill during the study period were excluded from the study.

2.4. Sample Size and Sampling Procedures. The sample size was calculated using single population proportion formula with the assumption of 95\% confidence interval, 5\% margin of error, $61.9 \%$ of maternal satisfaction [14], and $10 \%$ of nonresponse rate. The final sample size for the study was found to be 398. There are five public hospitals in North Wollo Zone; among these, three hospitals were selected purposefully based on service provision to the public and provision of basic obstetrics and newborn care. Numbers of study subjects in each hospital were determined by proportion to population size from reviewing the average three-month delivery service report. The study participants were selected by systematic sampling method when the mothers were discharged from postnatal unit, and exit interview was performed after the delivery period.

2.5. Variables and Measurements. Satisfaction: the overall maternal satisfaction was measured based on the answer for satisfaction related question using a five point Likert scale, and the mean score of satisfaction was 64.66. Above the mean score of satisfaction were considered as satisfied "yes," and below the mean as dissatisfied "no" [18]. During analysis, the responses of "very satisfied" and "satisfied" were classified as satisfied and responses of "very dissatisfied," "dissatisfied," and "neutral" as unsatisfied. For the overall satisfaction level, those who were satisfied in greater or equal to the mean score of the items were categorized under satisfied, and those who were satisfied in less than mean score of the items were categorized as unsatisfied.

Waiting time: the time between admissions to the time seen by health-care professional.

Privacy: the state of being free from being observed or disturbed by other people. 
TABLE 1: Sociodemographic characteristics of mothers who gave birth in public hospitals of North Wollo Zone, Northeastern Ethiopia, $2019(N=398)$.

\begin{tabular}{|c|c|c|c|}
\hline Variables & Category & Frequency & Percentage \\
\hline \multirow{3}{*}{ Age } & $\leq 24$ years & 160 & 40.2 \\
\hline & $25-34$ years & 213 & 53.5 \\
\hline & $\geq 35$ years & 25 & 6.2 \\
\hline \multirow{3}{*}{ Marital status } & Married & 379 & 95.2 \\
\hline & Widowed & 14 & 3.5 \\
\hline & Others* & 5 & 1.3 \\
\hline \multirow{3}{*}{ Religion } & Orthodox & 329 & 82.7 \\
\hline & Muslim & 58 & 14.6 \\
\hline & Others** & 11 & 2.7 \\
\hline \multirow{4}{*}{$\begin{array}{l}\text { Educational } \\
\text { status }\end{array}$} & Unable to read and write & 235 & 59.0 \\
\hline & Able to read and write & 86 & 21.6 \\
\hline & Primary education & 33 & 8.3 \\
\hline & $\begin{array}{c}\text { Secondary education } \\
\text { and above }\end{array}$ & 44 & 11.1 \\
\hline \multirow{3}{*}{$\begin{array}{l}\text { Occupational } \\
\text { status }\end{array}$} & Housewife & 265 & 66.6 \\
\hline & Civil servant & 109 & 27.4 \\
\hline & Private employee & 24 & 6.0 \\
\hline \multirow{2}{*}{ Residence } & Urban & 298 & 74.9 \\
\hline & Rural & 100 & 25.1 \\
\hline \multirow{2}{*}{ Family size } & $\leq 4$ & 352 & 88.4 \\
\hline & $>4$ & 46 & 11.6 \\
\hline \multirow{2}{*}{$\begin{array}{l}\text { Monthly } \\
\text { income }\end{array}$} & $<2000$ ETB & 176 & 44.2 \\
\hline & $\geq 2000 \mathrm{ETB}$ & 222 & 55.8 \\
\hline
\end{tabular}

*others (single and divorce); ${ }^{* *}$ others (Protestant, Catholic).

2.6. Data Collection Tool and Techniques. The data was collected by structured questionnaire which have three parts. The first part asks about sociodemographic information of mothers, and the second part is all about obstetric factors of the mother. Finally, the satisfaction of mothers was measured using questions which were adopted from Donabedian quality assessment framework [23] presented using a 5-point Likert scale ranging from very dissatisfied to very satisfied. The first draft of the English questionnaire was translated to Amharic language by independent translators then back to English language to check for consistency. Privacy and confidentiality were assured by not writing the name of the study subjects.

2.7. Data Quality Control. Two days training were given for data collectors and supervisors on how to ask and fill the questionnaire and how to approach the respondents. On each data collection day, the collected data were reviewed and checked for mistakes, legibility of handwriting, completeness, and consistency, and any mistake or ambiguity were cleared by principal investigator and supervisor; any problems faced in the time of data collection were discussed, and immediate solution was taken. The questionnaire was
TABLE 2: Obstetric characteristic of mothers who gave birth at a public hospital in North Wollo Zone, Northeast Ethiopia, 2019 $(n=398)$.

\begin{tabular}{|c|c|c|c|}
\hline Variables & Category & Frequency & Percentage \\
\hline \multirow{2}{*}{ Age at first pregnancy } & $\leq 18$ years & 368 & 92.5 \\
\hline & $>18$ years & 30 & 7.5 \\
\hline \multirow{2}{*}{ Gravidity } & Primigravida & 235 & 59.0 \\
\hline & Multigravida & 163 & 41.00 \\
\hline \multirow{2}{*}{ Parity } & Primipara & 276 & 69.3 \\
\hline & Multipara & 122 & 30.7 \\
\hline \multirow{2}{*}{ Neonatal death } & Yes & 1 & 0.3 \\
\hline & No & 397 & 99.7 \\
\hline \multirow{2}{*}{ Stillbirth } & Yes & 3 & 0.8 \\
\hline & No & 395 & 99.2 \\
\hline \multirow{2}{*}{ History of abortion } & Yes & 18 & 4.5 \\
\hline & No & 380 & 95.5 \\
\hline \multirow{2}{*}{ Labouring time } & $\leq 6$ hours & 259 & 65.1 \\
\hline & $>6$ hours & 139 & 34.9 \\
\hline \multirow{2}{*}{$\begin{array}{l}\text { Travelling time to } \\
\text { reach health facility }\end{array}$} & $\leq 30$ minutes & 235 & 59.0 \\
\hline & $>30$ minutes & 163 & 41.0 \\
\hline \multirow{2}{*}{$\begin{array}{l}\text { Time to be seen by the } \\
\text { physician }\end{array}$} & $\leq 20$ minutes & 294 & 73.9 \\
\hline & $>20$ minutes & 140 & 26.1 \\
\hline \multirow{2}{*}{$\begin{array}{l}\text { Waiting time after } \\
\text { delivery }\end{array}$} & $\leq 24$ hours & 382 & 96.0 \\
\hline & $>24$ hours & 16 & 4.0 \\
\hline \multirow{2}{*}{ ANC follow up } & Yes & 375 & 94.2 \\
\hline & No & 23 & 5.8 \\
\hline \multirow{2}{*}{$\begin{array}{l}\text { Frequency of ANC } \\
\text { follow up }(n=375)\end{array}$} & $<4$ visits & 230 & 61.3 \\
\hline & $\geq 4$ visits & 145 & 38.7 \\
\hline \multirow{3}{*}{$\begin{array}{l}\text { Reason for } \\
\text { institutional delivery }\end{array}$} & $\begin{array}{l}\text { Recommended } \\
\text { by others }\end{array}$ & 160 & 40.2 \\
\hline & $\begin{array}{l}\text { Satisfied with a } \\
\text { previous birth }\end{array}$ & 159 & 39.9 \\
\hline & $\begin{array}{c}\text { Referred from } \\
\text { other HFs }\end{array}$ & 79 & 19.8 \\
\hline \multirow{2}{*}{ Status of pregnancy } & Wanted & 381 & 95.7 \\
\hline & Unwanted & 17 & 4.3 \\
\hline \multirow{3}{*}{ Mode of delivery } & SVD & 365 & 91.7 \\
\hline & $\begin{array}{l}\text { Instrumental } \\
\text { delivery }\end{array}$ & 16 & 4.0 \\
\hline & $\begin{array}{c}\text { Caesarean } \\
\text { section }\end{array}$ & 17 & 4.3 \\
\hline \multirow{3}{*}{ Mode of transport } & Walking & 3 & 0.8 \\
\hline & Public transport & 204 & 51.2 \\
\hline & Ambulance & 191 & 48.0 \\
\hline \multirow{2}{*}{ Getting adequate meal } & Yes & 358 & 89.9 \\
\hline & No & 40 & 10.1 \\
\hline
\end{tabular}




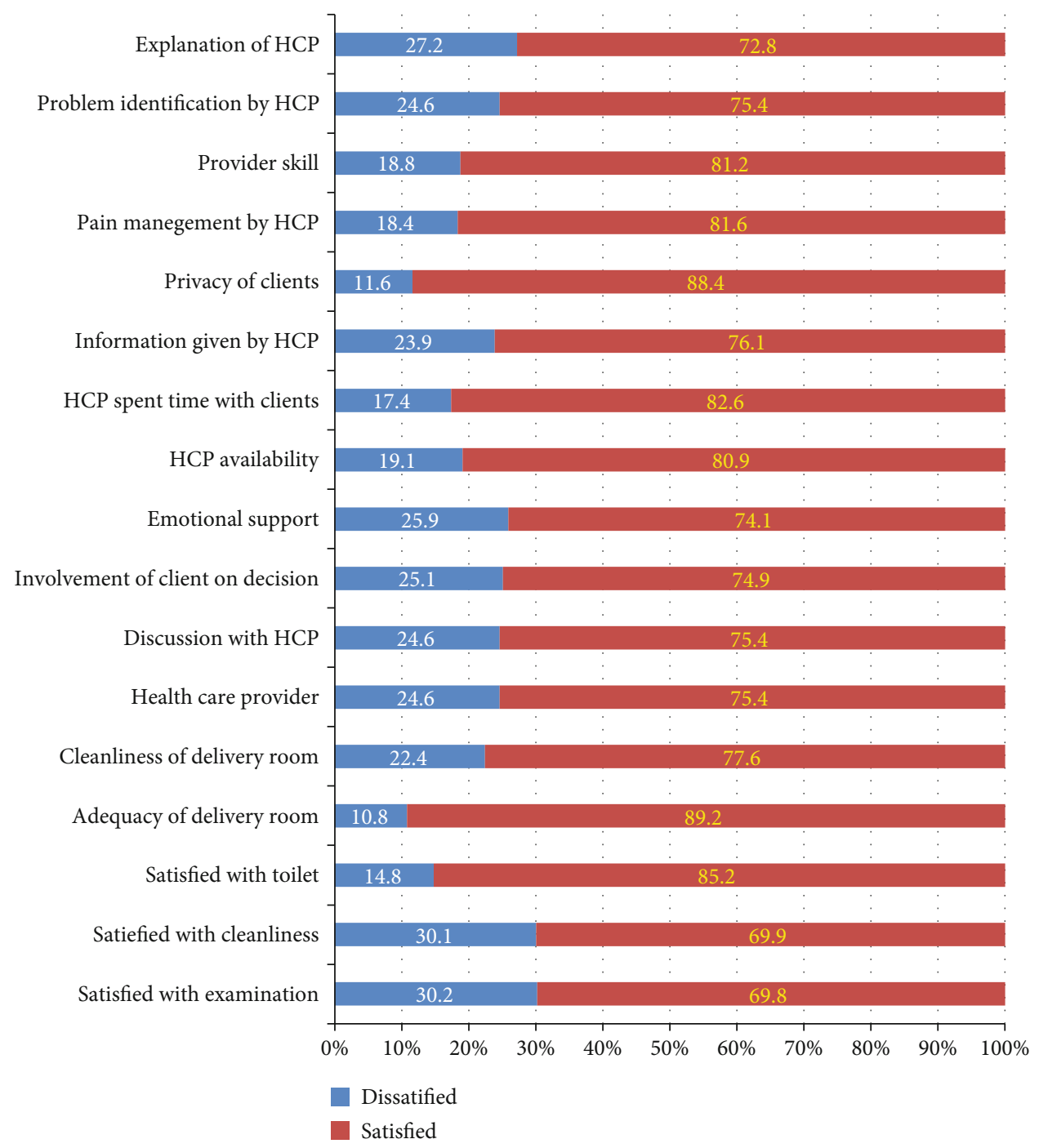

FIGURE 1: Maternal satisfaction among mothers who gave birth at public hospitals in North Wollo Zone, Northeast Ethiopia, 2019 ( $n=398$ ).

pretested on $5 \%$ of sample size at Wadila Primary Hospital before the actual data collection to see the accuracy of responses, language clarity, and appropriateness of the tools. The necessary amendments were done based on the findings of the pretest. The amended tools were used for actual data collection at the selected health facilities.

2.8. Data Processing and Analysis. The collected data were coded, cleaned, and entered into Epi data version 4.2 and exported to SPSS window version 24 for analysis. Bivariate analysis, crude odds ratio with $95 \% \mathrm{CI}$, was used to see the association between each independent variable and the outcome variable by using binary logistic regression. All variables with $P \leq 0.25$ in the bivariable analysis were included in the final model of multivariable analysis in order to control all possible confounders. Adjusted odds ratio (AOR) with 95\% CI were estimated to identify factors associated with mothers' satisfaction towards intrapartum nursing care using multivariable logistic regression analysis. Level of statistical significance was declared at $P$ value $<0.05$.

\section{Results}

3.1. Sociodemographic Characteristics of Respondents. A total of 398 delivering mothers from three public hospitals participated in the study, making a response rate of $100 \%$. Of the total study participants, 171 (43\%) of the women were from Woldia General Hospital, 113 (28.4\%) were from Kobo Primary Hospital, and the rest 114 (28.6\%) were from Lalibela Primary Hospital. The mean age of the mothers was 27.68 $( \pm 5.08$ SD). About $59 \%$ of the women were unable to write and read, and the majority, 95.2\%, were married. Two hundred sixty-five $(66.6 \%)$ of study participants were housewives, and 298 (74.9\%) of mothers came from urban areas. Regarding family size majority, 352 (88.4\%) of the study subjects had less than or equal to four-family size (Table 1).

3.2. Obstetric Characteristics of Respondents. Regarding age at first pregnancy majority, 368 (92.5\%) were married before the age of 18 years. Concerning gravidity and parity, 235 (59\%) were primigravida and $276(69.3 \%)$ were primipara. Almost all, 397 (99.7\%), had not experienced neonatal death, 
TABLE 3: Factors associated with maternal satisfaction with intrapartum care among mothers who gave birth at a public hospital in North Wollo Zone, $2019(n=398)$.

\begin{tabular}{|c|c|c|c|c|c|}
\hline \multirow[b]{2}{*}{ Variable } & \multirow[b]{2}{*}{ Category } & \multicolumn{2}{|c|}{ Maternal satisfaction } & \multirow[b]{2}{*}{ COR $(95 \% \mathrm{CI})$} & \multirow[b]{2}{*}{ AOR (95\% CI) } \\
\hline & & $\begin{array}{l}\text { Satisfied } \\
\text { No }(\%)\end{array}$ & $\begin{array}{l}\text { Dissatisfied } \\
\text { No }(\%)\end{array}$ & & \\
\hline \multirow{3}{*}{ Age } & $\leq 24$ & $104(65.0)$ & $56(35.0)$ & $2.78(1.17-6.61)$ & $1.52(0.38-6.17)$ \\
\hline & $25-34$ & $89(41.8)$ & $124(58.2)$ & $1.07(0.46-2.51)$ & $0.49(0.0 .12-1.91)$ \\
\hline & $>34$ & $10(40.0)$ & $15(60.0)$ & 1 & 1 \\
\hline \multirow{3}{*}{ Educational level } & No formal education & $154(48.0)$ & $167(52.0)$ & $0.39(0.19-0.77)$ & $0.99(0.40-2.46)$ \\
\hline & Primary education & $18(54.5)$ & $15(45.5)$ & $0.50(0.19-1.29)$ & $1.15(0.37-3.53)$ \\
\hline & Secondary education and above & $31(70.5)$ & $13(29.5)$ & 1 & 1 \\
\hline \multirow{2}{*}{ Pregnancy status } & Wanted & $197(51.7)$ & $184(48.3)$ & $1.96(0.71-5.41)$ & $1.63(0.50-5.28)$ \\
\hline & Unwanted & $6(35.3)$ & $11(64.7)$ & 1 & 1 \\
\hline \multirow{2}{*}{ Parity } & Primipara & $189(53.5)$ & $164(46.5)$ & 1 & 1 \\
\hline & Multipara & $14(31.1)$ & $31(68.9)$ & $0.39(0.20-0.76)$ & $0.54(0.24-1.22)$ \\
\hline \multirow{2}{*}{ Residence } & Rural & $68(68.0)$ & $32(32.0)$ & $2.57(1.59-4.14)$ & $2.03(1.05-3.93)^{*}$ \\
\hline & Urban & $135(45.3)$ & $163(54.7)$ & 1 & 1 \\
\hline \multirow{2}{*}{ Gravidity } & Primigravida & $163(54.5)$ & $136(45.5)$ & 1 & 1 \\
\hline & Multigravida & $40(40.4)$ & $59(59.6)$ & $0.57(0.36-0.89)$ & $1.36(0.70-2.64)$ \\
\hline \multirow{2}{*}{ Mode of delivery } & SVD & $196(53.7)$ & $169(46.3)$ & 1 & 1 \\
\hline & Operative delivery & $7(21.2)$ & $26(78.8)$ & $0.23(0.09-0.54)$ & $0.74(0.22-2.37)$ \\
\hline \multirow{2}{*}{ Time to be seen by HCP } & $\leq 20$ minutes & $168(57.1)$ & $126(42.9)$ & $2.63(1.65-4.20)$ & $2.82(1.46-5.46)^{* *}$ \\
\hline & $>20$ minutes & $35(33.7)$ & $69(66.3)$ & 1 & 1 \\
\hline \multirow{2}{*}{ Getting adequate meal } & Yes & $194(54.2)$ & $164(45.8)$ & $4.07(1.89-8.80)$ & $3.96(1.13-13.83)^{* * *}$ \\
\hline & No & $9(22.5)$ & $31(77.5)$ & 1 & 1 \\
\hline \multirow{2}{*}{ ANC follow-up } & Yes & $183(48.8)$ & $192(51.2)$ & 1 & 1 \\
\hline & No & $18(78.3)$ & $5(21.7)$ & $3.78(1.65-14.77)$ & $3.73(1.12-12.57)^{* * * *}$ \\
\hline \multirow{2}{*}{ Waiting after delivery } & $\leq 24$ hrs. & $173(55.6)$ & $138(44.4)$ & $2.38(1.45-3.91)$ & $1.44(0.80-2.58)$ \\
\hline & $>24$ hrs. & $30(34.5)$ & $57(65.5)$ & 1 & 1 \\
\hline
\end{tabular}

Significant at ${ }^{*} P=0.035,{ }^{* *} P=0.002,{ }^{* * *} P=0.031$, and ${ }^{* * * *} P=0.034$.

and 395 (99.2\%) had not experienced a history of stillbirth. Concerning antenatal care follow-up, 375 (94.2\%) had a history of ANC follow-up; of them, 230 (61.3\%) had less than four visits. Regarding pregnancy status, 381 (95.7\%) were wanted and majority, 365 (91.7\%) mothers, delivered through spontaneous vaginal delivery (Table 2).

3.3. The Satisfaction of Labouring Mothers. Among 398 study participants, $51.0 \%$ of respondents were satisfied by the provision of hospital overall intrapartum nursing care. Among 398 study participants, $69.8 \%$ of labouring women were satisfied with examination, $77.6 \%$ with cleanliness, $85.2 \%$ with toilet, $89.2 \%$ with adequacy of delivery room, $75.4 \%$ with problem identification of health-care provider, and $88.4 \%$ with privacy of clients (Figure 1).

3.4. Factors Associated with Maternal Satisfaction. Bivariate and multivariate logistic regressions were conducted to examine the association between dependent and inde- pendent variables. First, on bivariate logistic regression analysis, those variables that had a significant association with the dependent variables with $P$ values of less than or equal to 0.25 were entered to multivariate logistic regression. In the multivariable model, residence, time to be seen by a health-care provider, ANC follow-up, and getting adequate meal had showed statistically significant association with maternal satisfaction on intrapartum nursing care.

Mothers who came from rural residents were almost two times more likely satisfied than urban residents (AOR: 2.03; 95\% CI: 1.05-3.93). Mothers who were seen by health-care providers in less than 20 minutes were more likely satisfied as compared with the counterparts (AOR: 2.82; 95\% CI: 1.46-5.46). Mothers who had not a history of ANC followup (AOR: 3.73; 95\% CI: 1.12-12.57) and getting an adequate meal (AOR: 3.96; 95\% CI: 1.13-13.83) were almost four times more likely satisfied as compared with their counterparts (Table 3). 


\section{Discussion}

Generally, this study addresses the magnitude of maternal satisfaction with intrapartum nursing care and its associated factors among mothers who gave birth at North Wollo Zone public hospitals, Northeastern Ethiopia. Time to be seen with health-care providers, ANC follow-up, getting adequate meal, and residence were factors associated with maternal satisfaction with intrapartum nursing care.

This study revealed that the overall satisfaction of mothers on delivery service was found to be $51.0 \%$ (95\% CI: $46.2 \%-56 \%$ ), which is in line with a study conducted in Nepal (55.5\%) [19] and Nairobi Kenya (56\%) [24], higher than the study, which was conducted in Eritrea $(20.8 \%)$ [25], Gondar Ethiopia (31.3\%) [16], and Addis Ababa Ethiopia (19\%) [9]. The possible deference may be due to improvement of intrapartum nursing care for labouring mothers due to high government concern for mothers and newborns to reduce maternal and neonatal mortality and morbidity. However, it was lower than a study conducted in Egypt (78.5\%) [12], Wolaita Zone (82.9\%) [26], Southern Ethiopia (90.2\%) [27], Jimma University Specialized Hospital (77\%) [28], Assella Hospital (80.7\%) [29], Mekelle Ethiopia (79.7\%) [30], Debre Markos town (81.7\%) [15], and Felege Hiwot Referral Hospital Northwest Ethiopia (74.9\%) [31]. This difference might be due to a real difference in the quality of services provided, the expectation of mothers, or the type of health facilities since most of them were primary hospitals.

In this study, being rural residents were almost two times more likely to be satisfied as compared with urban residents. This was in line with the study conducted in Wolaita Zone Ethiopia [26]. This might be due to mothers who came from rural residents had low expectation of different services and they became satisfied with the care they obtained at the intrapartum period. Similarly, those study participants who waited 20 minutes and less to be seen with health-care providers were 2.82 times more likely satisfied than their counterparts. This is in line with the study conducted in referral hospitals of Amhara region, Ethiopia [14], Assella Hospital [29]. This might be because long waiting time resulted in dissatisfaction due to poor cleanliness of toilet, the cost paid to service, and poor waiting area cleanliness and comfort.

Mothers who had not a history of ANC follow-up were 3.73 times more likely satisfied with intrapartum nursing care as compared with those mothers who had ANC follow-up which is supported with the study conducted in Assella Hospital [29] and Felege Hiwot Referral Hospital [31]. This might be due to the fact that getting awareness during counselling session of ANC follow-up and media exposure results in better expectation on quality of service greater than the real service which results in low satisfaction with intrapartum nursing care. Mothers getting adequate meals were almost four times more likely satisfied with intrapartum care as compared with their counterparts. This might be due to the fact that mothers who get a meal and other services which is similar to the service they get from their home results in better satisfaction.
4.1. Limitation of the Study. Findings might be subject to social desirability bias since interviews with mothers were conducted in the compounds of the health facilities.

\section{Conclusion}

In this study, the overall maternal satisfaction with intrapartum nursing care was low. Time to be seen with health-care providers, ANC follow-up, getting adequate meal, and residence were factors associated with maternal satisfaction with intrapartum care. Health-care providers should provide patient-centered care by fulfilling the mother's expectation as a crucial means to engage them with hospital delivery.

\section{Abbreviations \\ AOR: Adjusted odds ratio \\ ANC: Antenatal care \\ COR: Crude odds ratio \\ EDHS: Ethiopia demographic health survey \\ MMR: Maternal mortality ratio \\ PHCU: Primary health care units \\ SPSS: Statistical package for social science \\ SVD: Spontaneous vaginal delivery \\ WDU: Woldia University \\ WHO: World Health Organization.}

\section{Data Availability}

All related data has been presented within the manuscript. The dataset supporting the conclusions of this article is available from the authors on request.

\section{Ethical Approval}

Ethical approval was obtained from Woldia University, College of Health Sciences, Institutional Review Board (WDU/IRB). All the study participants were informed about the purpose of the study and their right to refuse. The participants enrolled in the study were informed about the study objectives, expected outcomes, benefits, and the risks associated with it. In this study, all the participants were above the age of 18 , and written consent was taken from all the participants before the interview.

\section{Conflicts of Interest}

The authors declared that they have no competing interests.

\section{Authors' Contributions}

$\mathrm{AD}$ and $\mathrm{DA}$ initiated the research, wrote the research proposal, conducted the fieldwork, supervised data entry, analyzed the data, and wrote the manuscript. GG and RN participated in refining the research proposal, analyzed the data, and wrote the report. All authors read and approved the final manuscript. 


\section{Acknowledgments}

The authors would like to thank data collectors and supervisors for their invaluable effort to make this study real. The author's deep gratitude also goes to study subjects who were volunteered and took their time to give all the relevant information for the study.

\section{References}

[1] UN, United Nations Transforming our world, the 2030 Agenda for Sustainable Development, 2015.

[2] WHO, UNICEF, Trends in Maternal Mortality and Morbidity, 1990-2010, WHO, UNICEF, UNFPA and The World Bank estimates, 2012.

[3] K. D. Rao, D. H. Peters, and K. Bandeen-Roche, "Towards patient-centered health services in India-a scale to measure patient perceptions of quality," International Journal for Quality in Health Care, vol. 18, no. 6, pp. 414-421, 2006.

[4] O. Chirdan, L. Lar, T. Afolaranmi, E. Inalegwu, C. Igoh, and G. Adah, "Client satisfaction with maternal health services comparism between public and private hospitals in Jos Nigeria," Jos Journal of Medicine, vol. 7, no. 1, pp. 1-9, 2006.

[5] B. Matejić, M. Š. Milićević, V. Vasić, and B. Djikanović, "Maternal satisfaction with organized perinatal care in Serbian public hospitals," BMC Pregnancy and Childbirth, vol. 14, no. 1, p. 14, 2014.

[6] A. Srivastava, B. I. Avan, P. Rajbangshi, and S. Bhattacharyya, "Determinants of women's satisfaction with maternal health care: a review of literature from developing countries," BMC Pregnancy and Childbirth, vol. 15, no. 1, p. 97, 2015.

[7] L. Lewis, Y. L. Hauck, F. Ronchi, C. Crichton, and L. Waller, "Gaining insight into how women conceptualize satisfaction: Western Australian women's perception of their maternity care experiences," BMC Pregnancy and Childbirth, vol. 16, no. 1, p. 29, 2016

[8] R. Tesfaye, A. Worku, W. Godana, and B. Lindtjorn, "Client satisfaction with delivery care service and associated factors in the public health facilities of Gamo Gofa zone, Southwest Ethiopia: In a Resource Limited Setting," Obstetrics and Gynecology International, vol. 2016, Article ID 5798068, 7 pages, 2016.

[9] T. Demas, T. Getinet, D. Bekele, T. Gishu, M. Birara, and Y. Abeje, "Women's satisfaction with intrapartum care in St Paul's hospital millennium medical college Addis Ababa Ethiopia: a cross sectional study," BMC Pregnancy and Childbirth, vol. 17, no. 1, p. 253, 2017.

[10] G. Fisseha, Y. Berhane, A. Worku, and W. Terefe, "Quality of the delivery services in health facilities in Northern Ethiopia," BMC Health Services Research, vol. 17, no. 1, p. 187, 2017.

[11] I. C. F. CSA, Ethiopia Demographic and Health Survey; Central Statistical Agency Addis Ababa, Ethiopia, The DHS Program ICF, Rockville, Maryland, USA, 2016.

[12] W. Sayed, D. E. M. Abd ElAal, H. S. Mohammed, A. M. Abbas, and K. M. Zahran, "Maternal satisfaction with delivery services at tertiary university hospital in upper Egypt, is it actually satisfying?," International Journal of Reproduction, Contraception, Obstetrics and Gynecology, vol. 7, no. 7, article 2547, 2018.

[13] T. Melese, Y. Gebrehiwot, D. Bisetegne, and D. Habte, "Assessment of client satisfaction in labor and delivery services at a maternity referral hospital in Ethiopia," The Pan African Medical Journal, vol. 17, p. 76, 2014.

[14] A. Tayelgn, D. T. Zegeye, and Y. Kebede, "Mothers' satisfaction with referral hospital delivery service in Amhara region, Ethiopia," BMC Pregnancy and Childbirth, vol. 11, no. 1, p. 78, 2011.

[15] K. Bitew, M. Ayichiluhm, and K. Yimam, "Maternal satisfaction on delivery service and its associated factors among mothers who gave birth in public health facilities of Debre Markos town, Northwest Ethiopia," BioMed Research International, vol. 2015, Article ID 460767, 6 pages, 2015.

[16] K. T. Gashaye, A. T. Tsegaye, G. Shiferaw, A. G. Worku, and S. M. Abebe, "Client satisfaction with existing labor and delivery care and associated factors among mothers who gave birth in university of Gondar teaching hospital; Northwest Ethiopia: institution based cross-sectional study," PLoS One, vol. 14, no. 2, article $\mathrm{e} 0210693,2019$.

[17] M. Oikawa, A. Sonko, E. O. Faye, P. Ndiaye, M. Diadhiou, and M. Kondo, "Assessment of maternal satisfaction with facilitybased childbirth care in the rural region of Tambacouda, Senegal," African Journal of Reproductive Health, vol. 18, no. 4, pp. 95-104, 2014.

[18] P. Jha, M. Larsson, K. Christensson, and A. Skoog Svanberg, "Satisfaction with childbirth services provided in public health facilities: results from a cross- sectional survey among postnatal women in Chhattisgarh, India," Global Health Action, vol. 10, no. 1, article 1386932, 2017.

[19] A. Panth and P. Kafle, "Maternal satisfaction on delivery service among postnatal mothers in a government hospital, Mid-Western Nepal," Obstetrics and Gynecology International, vol. 2018, Article ID 4530161, 11 pages, 2018.

[20] EPHI and Ethiopian Public Health Institute (EPHI) [Ethiopia] and ICF, Ethiopia Mini Demographic and Health Survey 2019: Key Indicators, EPHI and ICF, Rockville, Maryland, USA, 2019, March 2020, https://dhsprogram.com/pubs/pdf/PR120/ PR120.pdf.

[21] WHO, "World Health Organisation recommendations on antenatal care for a positive pregnancy experience," 2016, http://apps.who.int/iris/bitstream/10665/250796/1/97892 41549912-eng.pdf.

[22] CSA I and Central Statistical Agency (CSA) (Ethiopia) and ICF, Ethiopia Demographic and Health Survey 2016, CSA and ICF, Addis Ababa, Ethiopia, and Rockville, Maryland, USA, 2016, July 2019, https://dhsprogram.com/pubs/pdf/ FR328/FR328.pdf.

[23] A. Donabedian, An Introduction to Quality Assurance in Health Care, Oxford University Press, 2002.

[24] E. S. Bazant and M. A. Koenig, "Women's satisfaction with delivery care in Nairobi's informal settlements," International Journal for Quality in Health Care, vol. 21, no. 2, pp. 79-86, 2009.

[25] M. M. Kifle, F. A. Ghirmai, S. A. Berhe, W. S. Tesfay, Y. T. Weldegebriel, and Z. T. Gebrehiwet, "Predictors of Women's Satisfaction with Hospital-Based Intrapartum Care in Asmara Public Hospitals, Eritrea," Obstetrics and Gynecology International, vol. 2017, Article ID 3717408, 7 pages, 2017.

[26] B. Yohannes, M. Tarekegn, and W. Paulos, "Mothers' utilization of antenatal care and their satisfaction with delivery services in selected public health facilities of wolaita zone, southern Ethiopia," International Journal of Scientific \& Technology Research, vol. 2, no. 2, pp. 74-85, 2013. 
[27] Z. Dewana, "Quality of delivery service at public health facilities in Arba Minch District, Gamo Gofa Zone, Southern Ethiopia," Journal of Gynecology and Obstetrics, vol. 5, no. 2, pp. 31-36, 2017.

[28] F. Assefa, A. Mosse, and Y. H/Michael, “Assessment of clients' satisfaction with health service deliveries at Jimma University specialized hospital," Ethiopian Journal of Health Sciences, vol. 21, no. 2, pp. 101-109, 2011.

[29] R. Amdemichael, M. Tafa, and H. Fekadu, "Maternal satisfaction with the delivery services in Assela Hospital, Arsi Zone, Oromia Region, Ethiopia,2013," Gynecology \& Obstetrics, vol. 4, no. 12, article 1000257, 2014.

[30] T. Marama, H. Bayu, M. Merga, and W. Binu, "Patient satisfaction and associated factors among clients admitted to obstetrics and gynecology wards of public hospitals in Mekelle town, Ethiopia: an institution-based cross-sectional study," Obstetrics and Gynecology International, vol. 2018, Article ID 2475059, 9 pages, 2018.

[31] M. E. Mekonnen, W. A. Yalew, and Z. A. Anteneh, "Women's satisfaction with childbirth care in Felege Hiwot referral hospital, Bahir Dar city, Northwest Ethiopia, 2014: cross sectional study," BMC Research Notes, vol. 8, no. 1, p. 528, 2015. 